\title{
KARAKTERISASI DARI HIMPUNAN $g$-INVERS PADA MATRIKS FUZZY
}

\author{
HILDA FAUZANA, NOVA NOLIZA BAKAR, MONIKA RIANTI HELMI \\ Program Studi Matematika, \\ Fakultas Matematika dan Ilmu Pengetahuan Alam, Universitas Andalas, \\ Kampus UNAND Limau Manis Padang, Indonesia. \\ email : hildafauzana14@gmail.com
}

\begin{abstract}
Abstrak. Invers yang tergeneralisasi ( $g$-invers) merupakan perluasan dari konsep invers matriks. $G$-invers pada matriks fuzzy dinamakan matriks regular. Pada tulisan ini mengkaji karakterisasi dari himpunan $g$-invers pada matriks fuzzy. Selanjutnya diperoleh karakterisasi dari himpunan $g$-invers pada matriks fuzzy yaitu misalkan $A$ adalah matriks fuzzy berukuran $m \times n$. Jika $G^{*}$ dan $G$ adalah $g$-invers dari $A$ dengan $G^{*} \geq G$, maka $G+H$ adalah $g$-invers dari $A$ untuk semua matriks fuzzy $H$ berukuran $n \times m$. Sehingga $A_{G}\{1\}, A_{G}\{1,3\}$ dan $A_{G}\{1,4\}$ adalah himpunan semua $g$-invers, $\{1,3\}$ invers, dan $\{1,4\}$ invers dari $A$ yang mendominasi $G$.

Kata Kunci: Invers yang tergeneralisasi (g-invers), matriks fuzzy, matriks regular, $\{1,3\}$ invers, $\{1,4\}$ invers.

$\begin{array}{lll}\text { Diterima } & : & \text { 6 Juli 2018 } \\ \text { Direvisi } & : & 15 \text { September 2018 } \\ \text { Dipublikasikan } & : & \text { 21 Desember 2018 }\end{array}$
\end{abstract}

\section{Pendahuluan}

Konsep dari suatu matriks sangat berguna untuk menyelesaikan permasalahan dalam ilmu matematika modern, salah satunya adalah penyelesaian persamaan matriks dengan menggunakan konsep invers matriks. Perluasan dari konsep invers matriks dideskripsikan oleh E.H Moore pada tahun 1920, salah satunya adalah jenis invers matriks yang dikenal dengan nama Invers yang tergeneralisasi ( $g$-invers). Kemudian pada tahun 1955 Roger Penrose berhasil mendeskripsikan empat persamaan yang harus dipenuhi untuk menentukan $g$-invers. Persamaan tersebut dikenal dengan nama persamaan Penrose.

Himpunan fuzzy merupakan himpunan yang anggota-anggotanya berada dalam interval $[0,1]$. Matriks fuzzy adalah matriks yang entri-entrinya bilangan yang berada pada selang tutup [0,1]. Generalisasi invers ( $g$-invers) adalah salah satu jenis invers matriks. Tidak hanya pada matriks biasa, $g$-invers juga berlaku pada matriks fuzzy. Matriks fuzzy yang memiliki $g$-invers disebut matriks fuzzy regular. Pada paper ini dibahas bagaimana karakterisasi dari himpunan $g$-invers pada matriks fuzzy.

\section{Tinjauan Pustaka}

Berikut adalah beberapa definisi dan materi dasar pada matriks fuzzy. 
Definisi 2.1. [4] Matriks $A=\left[a_{i j}\right]$ dikatakan matriks fuzzy jika $a_{i j} \in[0,1]$, dengan $a_{i j}$ adalah entri dari matriks A yang terletak pada baris ke-i dan kolom ke-j.

Definisi 2.2. [4] Misalkan matriks fuzzy $A=\left[a_{i j}\right]$ dan $B=\left[b_{i j}\right]$. Matriks $A \geq B$ jika $a_{i j} \geq b_{i j}$ dan $A \leq B$ jika $a_{i j} \leq b_{i j}, \forall i, j$.

Definisi 2.3. [3] Misalkan $a, b \in F$ dimana $F=[0,1]$ matriks atas aljabar fuzzy dengan operasi penjumlahan dan perkalian pada $a, b$ didefinisikan sebagai berikut:

$$
a+b=\max \{a, b\}, \quad a . b=\min \{a, b\}
$$

Definisi 2.4. [4] Misalkan $A=\left[a_{i j}\right]$ dan $B=\left[b_{i j}\right]$ adalah matriks-matriks fuzzy berukuran $m \times n$, maka penjumlahan dari $A, B$ didefinisikan sebagai berikut,

$$
\begin{aligned}
A+B & =\left[a_{i j}+b_{i j}\right] \\
& =\left[\max \left\{a_{i j}, b_{i j}\right\}\right] .
\end{aligned}
$$

Definisi 2.5. [4] Misalkan $A=\left[a_{i j}\right]$ adalah matriks fuzzy berukuran $m \times p$ dan $B=\left[b_{i j}\right]$ adalah matriks fuzzy berukuran $p \times n$, maka perkalian dari $A, B$ didefinisikan sebagai berikut,

$$
\begin{aligned}
A B & =\left[a_{i j} \cdot b_{i j}\right] \\
& =\left[\sum_{k=1}^{p} a_{i k} b_{k j}\right] \\
& =\left[\max _{k}\left\{\min \left\{a_{i k}, b_{k j}\right\}\right\}\right] .
\end{aligned}
$$

Proposisi 2.6. [2] Misalkan $A, B \in F_{m n}$, maka $A \leq B$ jika dan hanya jika $A+B=$ $B$.

Proposisi 2.7. [2] Misalkan $A, B \in F_{m n}$. Jika $A \leq B$ maka untuk setiap $C \in F_{n p}$, $A C \leq B C$ dan untuk setiap $D \in F_{p m}, D A \leq D B$.

Proposisi 2.8. [2] Misalkan $A, B, C$ dengan ukuran masing-masing $m \times n, n \times$ $p$ dan $p \times q$, maka berlaku:

$$
(A B) C=A(B C)
$$

Proposisi 2.9. [2] Misalkan matriks fuzzy $A, B, C$ dengan ukuran masing-masing $m \times n, n \times p, n \times p$, maka berlaku:

$$
A(B+C)=A B+A C
$$

Definisi 2.10. [4] Misalkan $A=\left[a_{i j}\right]$ dan $B=\left[b_{i j}\right] \in F_{m n}$ maka $A-B=\left[a_{i j}-\right.$ $\left.b_{i j}\right]_{m \times n}$ untuk setiap $A \geq B$.

Teorema 2.11. [2] Misalkan $A \in F_{m n}$ dan $B \in F_{n p}$, maka berlaku:

1. $\left(A^{T}\right)^{T}=A$.

2. $(A B)^{T}=B^{T} A^{T}$. 
Invers yang tergeneralisasi ( $g$-invers) merupakan perluasan dari konsep invers matriks. Empat persamaan yang dikenal sebagai persamaan Penrose yang menjadi dasar adanya invers yang tergeneralisasi ( $g$-invers) suatu matriks yaitu:

1. $A X A=A$.

2. $X A X=X$.

3. $(A X)^{*}=A X$.

4. $(X A)^{*}=X A$,

dimana $(A X)^{*}$ adalah tranpose konjugat dari $A X[1]$.

Karena entri-entri pada matriks fuzzy berada pada selang tutup [0,1], maka persamaan 3 dan 4 menjadi $(A X)^{T}=A X$ dan $(X A)^{T}=X A$ dengan $A$ adalah matriks fuzzy dan $X$ merupakan $g$-invers dari $A$.

Telah diketahui bahwa $g$-invers ada untuk matriks kompleks. Namun tidak demikian dengan matriks $f u z z y$, yaitu untuk $A \in F_{m n}$ dengan menggunakan definisi penjumlahan dan perkalian pada matriks fuzzy, persamaan matriks $A X A=A$ tidak selalu memiliki solusi $X$. Suatu matriks $X \in F_{n m}$ dikatakan invers yang tergeneralisasi ( $g$-invers) dari matriks $A \in F_{m n}$ jika memenuhi $A X A=A$ dengan menggunakan operasi penjumlahan dan perkalian pada matriks fuzzy [2].

Berikut adalah definisi $g$-invers pada matriks fuzzy.

Definisi 2.12. [2] Misalkan $A \in F_{m n}$. Jika $A$ adalah regular, maka g-invers dari $A$ dilambangkan sebagai $X$ dan $A\{1\}$ adalah himpunan dari semua $g$-invers dari $A$ yang memenuhi $A X A=A$.

Definisi 2.13. [2] Untuk $A \in F_{m n}$, jika terdapat $X \in F_{n m}$ sedemikian sehingga $A X A=A$ dan $X A X=X$, maka $X$ disebut invers semi atau $\{1,2\}$ invers dari $A$.

Himpunan $\{1,2\}$ invers dari $A$ dilambangkan sebagai $A\{1,2\}$.

Definisi 2.14. [2] Untuk $A \in F_{m n}$, suatu matriks $X \in F_{n m}$ dikatakan $\{1,3\}$ invers dari $A$ atau g-invers kuadrat terkecil dari $A$ jika $A X A=A$ dan $(A X)^{T}=(A X)$.

Definisi 2.15. [2] Untuk $A \in F_{m n}$, suatu matriks $X \in F_{n m}$ dikatakan $\{1,4\}$ invers dari $A$ atau g-invers norm minimum dari $A$ jika $A X A=A$ dan $(X A)^{T}=(X A)$.

\section{Karakterisasi dari Himpunan $g$-Invers pada Matriks Fuzzy}

Pada bagian ini, akan dibahas bagaimana karakterisasi dari himpunan $g$-invers pada matriks fuzzy.

Lema 3.1. [2] Untuk $A \in F_{m n}$ jika $G^{*}$ dan $G$ adalah g-invers dari $A$ sedemikian sehingga $G^{*} \geq G$, maka $G+H$ adalah g-invers dari $A$ untuk suatu $H \in F_{n m}$ sedemikian sehingga $G^{*} \geq G+H \geq G$.

Bukti. Misal $A \in F_{m n}, G^{*}$ dan $G$ adalah $g$-invers dari $A$ dengan $G^{*} \geq G$.

Akan ditunjukkan $G+H$ adalah $g$-invers dari $A$ untuk suatu $H \in F_{n m}$ sedemikian sehingga $G^{*} \geq G+H \geq G$, yaitu dengan menunjukkan bahwa $A(G+H) A=A$. 
Karena $G^{*} \geq G$, ambil $H=G^{*}-G$ untuk suatu $H \in F_{n m}$.

Karena $H=G^{*}-G$, maka $G^{*} \geq H$.

Dari $G^{*} \geq G$ dan $G^{*} \geq H$, maka

$$
G^{*} \geq G+H \geq G .
$$

Karena $G^{*}$ dan $G$ adalah $g$-invers dari $A$, maka

$$
A G^{*} A=A \operatorname{dan} A G A=A .
$$

Berdasarkan Proposisi 2.2.2

$$
G^{*} \geq G+H \geq G \Rightarrow A G^{*} A \geq A(G+H) A \geq A G A
$$

sehingga $A \geq A(G+H) A \geq A \Rightarrow A(G+H) A=A$.

Karena $A(G+H) A=A$ berarti $(G+H) \in A\{1\}$, maka $G+H$ adalah $g$-invers dari A.

Teorema 3.2. [2] Misal $A \in F_{m n}$ dan $G$ adalah g-invers dari A. Maka

$A_{G}\{1\}=\left\{G+H \mid\right.$ untuk semua matriks fuzzy $H \in F_{n m}$ sedemikian sehingga $\left.A \geq A H A\right\}$ adalah himpunan semua g-invers dari A yang mendominasi $G$.

Bukti. Misal $A \in F_{m n}$ dan $G$ adalah $g$-invers dari $A$. Akan ditunjukkan $A_{G}\{1\}=\left\{G+H \mid\right.$ untuk semua matriks fuzzy $H \in F_{n m}$ sedemikian sehingga $\left.A \geq A H A\right\}$ adalah himpunan semua $g$-invers dari $A$ yang mendominasi $G$.

Misal

$\mathcal{A}=\left\{G+H \mid\right.$ untuk semua matriks fuzzy $H \in F_{n m}$ sedemikian sehingga $\left.A \geq A H A\right\}$.

Misal $G^{*} \in A_{G}\{1\}$ dan $G \in A\{1\}$ sedemikian sehingga $G^{*} \geq G$. Ambil $H=G^{*}-G$ untuk semua $H \in F_{n m}$.

Berdasarkan Lemma 3.1, untuk $G^{*}$ dan $G$ adalah $g$-invers dari $A$ dengan $G^{*} \geq G$ maka $G+H$ adalah $g$-invers dari $A$. Karena $G+H$ adalah $g$-invers dari $A$, maka $A(G+H) A=A$.

Selanjutnya perhatikan bahwa

$$
\begin{aligned}
A(G+H) A=A & \Rightarrow A G A+A H A=A \\
& \Rightarrow A+A H A=A, \text { berdasarkan Proposisi 2.6, diperoleh } \\
& \Rightarrow A \geq A H A
\end{aligned}
$$

Karena $A \geq A H A$, sehingga $G+H \in \mathcal{A}$.

Sebaliknya, untuk setiap $G^{*} \in \mathcal{A}, G^{*}=G+H \geq G$, dengan $A \geq A H A$.

Akan ditunjukkan $G^{*} \in A_{G}\{1\}$ dengan menunjukkan $A G^{*} A=A$.

Perhatikan bahwa

$$
\begin{aligned}
A G^{*} A & =A(G+H) A \\
& =A G A+A H A, \text { karena } G \text { adalah } g-\text { invers dari } A \text { maka } A G A=A, \\
& =A+A H A, \text { dan karena } A \geq A H A \text { maka } \\
A G^{*} A & =A,
\end{aligned}
$$


sehingga $G^{*} \in A_{G}\{1\}$.

Jadi $A_{G}\{1\}=\left\{G+H \mid\right.$ untuk semua matriks fuzzy $H \in F_{n m}$ sedemikian sehingga $A \geq A H A\}$ adalah himpunan semua $g$-invers dari $A$ yang mendominasi $G$.

Teorema 3.3. [2] Himpunan $A\{1,3\}$ adalah solusi untuk semua $X$ dari $A X=A G$, dimana $G$ adalah $\{1,3\}$ invers dari $A$.

Bukti. Akan ditunjukkan bahwa untuk setiap $X \in A\{1,3\}$ adalah solusi dari $A X=A G$ dengan $G \in A\{1,3\}$.

Diketahui $G \in A\{1,3\}$ berarti

$$
A G A=A \text { dan }(A G)^{T}=A G, \quad(\text { Definisi } 2.14)
$$

karena $X \in A\{1,3\}$ berarti

$$
A X A=A \operatorname{dan}(A X)^{T}=A X . \quad(\text { Definisi 2.14) }
$$

Perhatikan bahwa

$$
\begin{aligned}
A G & =(A X A) G \\
& =(A X)(A G) \\
& =(A X)^{T}(A G)^{T} \\
& =\left(X^{T} A^{T}\right)\left(G^{T} A^{T}\right) \\
& =X^{T}\left(A^{T} G^{T} A^{T}\right) \\
& =X^{T}(A G A)^{T} \\
& =X^{T} A^{T} \\
& =(A X)^{T} \\
& =A X,
\end{aligned}
$$

sehingga $X$ adalah solusi dari $A X=A G$.

Sebaliknya, misal $A G=A X$ dan $G \in A\{1,3\}$ maka $G$ memenuhi $A G A=A$ dan $(A G)^{T}=A G$. Akan ditunjukkan $X \in A\{1,3\}$ dengan menunjukkan $A X A=A$ dan $(A X)^{T}=A X$.

Karena $A G=A X$ maka $A G A=A \Rightarrow A X A=A$ sehingga $X \in A\{1\}$, dan

$$
\begin{aligned}
A G=A X & \Rightarrow(A G)^{T}=(A X)^{T}, \text { karena } G \in A\{1,3\} \text { maka }(A G)^{T}=A G \\
& \Rightarrow A G=(A X)^{T}, \text { karena } A G=A X, \text { maka } \\
& \Rightarrow A X=(A X)^{T} \\
& \Rightarrow X \in A\{3\}
\end{aligned}
$$

Terbukti $X \in A\{1,3\}$.

Teorema 3.4. [2] Misal $A \in F_{m n}$ dan $G \in A\{1,3\}$, maka $A_{G}\{1,3\}=\left\{G+H \mid\right.$ untuk semua matriks fuzzy $H \in F_{n m}$ sedemikian sehingga $\left.A G \geq A H\right\}$ adalah himpunan semua $\{1,3\}$ invers dari A yang mendominasi $G$. 
Bukti. Misal $A \in F_{m n}$ dan $G \in A\{1,3\}$. Akan ditunjukkan $A_{G}\{1,3\}=\left\{G+H \mid\right.$ untuk semua matriks fuzzy $H \in F_{n m}$ sedemikian sehingga $\left.A G \geq A H\right\}$ adalah himpunan semua $\{1,3\}$ invers dari $A$ yang mendominasi $G$.

Misal $\mathcal{B}=\left\{G+H \mid\right.$ untuk semua matriks fuzzy $H \in F_{n m}$ sedemikian sehingga $\left.A G \geq A H\right\}$. Berdasarkan Teorema 3.3, dimana $X \in A\{1,3\}$ adalah solusi dari $A X=A G$ dengan $G \in A\{1,3\}$, jadi

$$
A(G+H)=A G \Rightarrow A G+A H=A G
$$

Berdasarkan Proposisi 2.6, maka diperoleh $A G \geq A H$. Karena $A G \geq A H$, sehingga $G+H \in \mathcal{B}$.

Sebaliknya, misal $G^{*} \in \mathcal{B}, G^{*}=G+H \geq G$ dengan $A G \geq A H$. Akan ditunjukkan $G^{*} \in A_{G}\{1,3\}$ dengan menunjukkan $A G^{*} A=A$ dan $\left(A G^{*}\right)^{T}=A G^{*}$. Pada Teorema 3.0.1 untuk $G^{*} \in A_{G}\{1\}$ telah terbukti $A G^{*} A=A$. Selanjutnya tinggal menunjukkan $\left(A G^{*}\right)^{T}=A G^{*}$.

Pada Teorema 3.0.2 untuk $X \in A\{1,3\}$ adalah solusi dari $A X=A G$ dengan $G \in A\{1,3\}$, jadi untuk $G^{*} \in A_{G}\{1,3\}$ dan $G \in A\{1,3\}$ maka $A G^{*}=A G$. Perhatikan bahwa,

$$
\begin{aligned}
\left(A G^{*}\right)^{T} & =(A(G+H))^{T} \\
& =(A G+A H)^{T}, \text { karena } A G \geq A H, \text { maka } \\
& =(A G)^{T} \\
& =A G, \text { karena } A G=A G^{*}, \text { maka } \\
& =A G^{*},
\end{aligned}
$$

sehingga $G^{*} \in A_{G}\{1,3\}$.

Jadi $A_{G}\{1,3\}=\left\{G+H \mid\right.$ untuk semua matriks fuzzy $H \in F_{n m}$ sedemikian sehingga $A G \geq A H\}$ adalah himpunan semua $\{1,3\}$ invers dari $A$ yang mendominasi $G$.

Teorema 3.5. [2] Himpunan $A\{1,4\}$ adalah solusi untuk semua $X$ dari $X A=G A$, dimana $G$ adalah $\{1,4\}$ invers dari $A$.

Teorema 3.6. [2] Misal $A \in F_{m n}$ dan $G \in A\{1,4\}$, maka $A_{G}\{1,4\}=\left\{G+H \mid\right.$ untuk semua matriks fuzzy $H \in F_{n m}$ sedemikian sehingga $\left.G A \geq H A\right\}$ adalah himpunan semua $\{1,4\}$ invers dari $A$ yang mendominasi $G$.

\section{Kesimpulan}

Pada tulisan ini diperoleh bagaimana karakterisasi dari himpunan $g$-invers pada matriks fuzzy, yaitu

(1) Misal diberikan matriks fuzzy $A$ berukuran $m \times n$. Jika $G^{*}$ dan $G$ adalah $g$ invers dari $A$ sedemikian sehingga $G^{*} \geq G$, maka $G+H$ adalah $g$-invers dari $A$ untuk suatu $H \in F_{n m}$ sedemikian sehingga $G^{*} \geq G+H \geq G$. 
(2) Misal diberikan matriks fuzzy $A$ berukuran $m \times n$ dan $G$ adalah $g$-invers dari $A$, maka $A_{G}\{1\}=\left\{G+H \mid\right.$ untuk semua matriks fuzzy $H \in F_{n m}$ sedemikian sehingga $A \geq A H A\}$ adalah himpunan semua $g$-invers dari $A$ yang mendominasi G.

(3) Misal $G$ adalah $\{1,3\}$ invers dari $A$, maka himpunan $A\{1,3\}$ adalah solusi untuk semua $X$ dari $A X=A G$.

(4) Misal diberikan matriks fuzzy $A$ berukuran $m \times n$ dan $G \in A\{1,3\}$, maka

$A_{G}\{1,3\}=\left\{G+H \mid\right.$ untuk semua matriks fuzzy $H \in F_{n m}$ sedemikian sehingga $\left.A G \geq A H\right\}$ adalah himpunan semua $\{1,3\}$ invers dari $A$ yang mendominasi $G$.

(5) Misal $G$ adalah $\{1,4\}$ invers dari $A$, maka himpunan $A\{1,4\}$ adalah solusi untuk semua $X$ dari $X A=G A$.

(6) Misal diberikan matriks fuzzy $A$ berukuran $m \times n$ dan $G \in A\{1,4\}$, maka $A_{G}\{1,4\}=\left\{G+H \mid\right.$ untuk semua matriks fuzzy $H \in F_{n m}$ sedemikian sehingga $\left.G A \geq H A\right\}$ adalah himpunan semua $\{1,4\}$ invers dari $A$ yang mendominasi $G$.

\section{Ucapan Terima kasih}

Penulis mengucapkan terimakasih kepada ibu Haripamyu, ibu Yanita dan ibu Hazmira Yozza yang telah memberikan masukan dan saran sehingga makalah ini dapat diselesaikan dengan baik.

\section{Daftar Pustaka}

[1] Ben-Israel, A and T.N.E Greville 2003. Generalized Inverses Theory And Application; Second Edition. Springer-Verlag New York, Inc, USA

[2] Meenakshi, A.R. 2008. Fuzzy Matrix Theory and Applications, MJP Publishers, India

[3] Pradhan, R and M. Pal. 2014. Some Results on Generalized Inverse of Intuitionistic Fuzzy Matrices, Journal Fuzzy Information and Engineering 6:133 145

[4] Sidky, F.I and E.G. Enam. 1992. Some Remarks on Section of a Fuzzy Matrix, J. K. A. U. Sci 4:145-155 